\title{
Implementation of An Electronic-Based Health Information System Maintaining the Paper Based System-Including: A Situational Analysis in Banso Baptist Hospital (BBH) In Cameroon
}

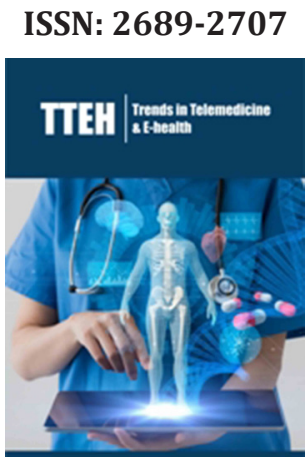

*Corresponding author: Promise Aseh Munteh, Assistant Lecturer, Director of Cooperation, Catholic University of Cameroon (CATUC)Bamenda

Submission: 酻 November 13, 2019

Published: 㘹December 06, 2019

Volume 2 - Issue 1

How to cite this article: Promise Aseh Munteh. Implementation of An Electronic-Based Health Information System Maintaining the Paper Based System-Including: A Situational Analysis in Banso Baptist Hospital (BBH) In Cameroon. Trends Telemed E-Health 2(1). TTEH. 000530. 2019. DOI: 10.31031/TTEH.2019.02.000530

Copyright@ Promise Aseh Munteh, This article is distributed under the terms of the Creative Commons Attribution 4.0 International License, which permits unrestricted use and redistribution provided that the original author and source are credited.
Promise Aseh Munteh*

Assistant Lecturer, Director of Cooperation, Catholic University of Cameroon (CATUC) Bamenda

\begin{abstract}
The aim of this study was to analyze the present paper based health information system, look at the advantages and disadvantages, compare these with the introduction of an electronic health information system, and come up with recommendations and implementation proposals for an electronic health information system while maintaining the paper based system so that the two continue to run side by side in Banso Baptist hospital. This was a retrospective hospital-based study. The instruments used for data collection were interviews, focus group discussions and review of past records in the medical records unit of the hospital. The main result revealed that, BBH attended to 36,681 in-patients and 405,239 out-patients for the period of five years and the numbers continue to increase per year. To handle the activities of all these patients manually has not been easy hence the need for an electronic health management information system. It was therefore, concluded that an electronic health management information system be introduced in the hospital but maintaining the paper-based system as a backup due to high levels of electricity cuts in the Region.
\end{abstract}

Keywords: Health; Health management information systems; Medical documentation; Information and communication technology; Data and health information technology

\section{Introduction}

It is important to note that very few countries have sufficient Health Information Systems (HIS) in place to permit adequate monitoring of progress towards the achievement of the United Nations Sustainable Development Goals with Cameroon inclusive. "With health care cost and quality assurance taking central role in the health care sector, increasing attention is being directed towards the potential of Health Information Technology (HIT) to lower health care spending and to improve efficiency, quality and safety of health care delivery".

A growing body of research has explored the potential of health IT systems to increase adherence to clinical guidelines, enhance disease surveillance, and decrease medication errors. A host of public and private organizations are focused on finding effective uses for IT in the health care sector. Some developments have already been made and we have health IT systems like Personal Health Records (PHRs) and Electronic Medical Records (EMRs) in use in hospitals especially in the Western World. Before the introduction of IT in the health care industry, it has been in existence in other industries; therefore, it is also important to understand the background of IT in general. Information Technology is tremendously changing our world. As a result, a new form of world is emerging whereby most of the activities are done with the assistance of this technology. Information and communication technology and the Internet have not affected only the IT professionals and those employees that use IT for their work on a regular basis but also the environment of the organization itself and the social world [1-9].

The world is heavily depending on the Information Technology as this can be seen in our personal life with the use of mobile phones, internet, and so on. The possibility to exchange documents and or information through the internet has paved the way for collaborating departments and units among hospitals. To date the IT Tools which are available for HIS usage have been of vital importance to success in hospital communication, co- ordination, 
sharing information and as well as decision making. Information Technology has undergone different stages of evolution since when it was discovered in the early 1900s. "Information Technology has become a major economic issue in America and the rest of the World. In 2008, American businesses spent about $\$ 840$ billion on information systems hardware, software and telecommunications equipment. In addition, they also spent another $\$ 900$ billion on business and management consulting and services much of which involved redesigning firms' business operations to take advantage of these new technologies." (Management Information SystemsManaging the Digital Firm).

The use of electronic health information systems in hospitals in Cameroon just like in most African countries is not popular. In fact, the manual system with all its disadvantages remains to be the only system used with Banso Baptist Hospital (BBH) inclusive.

\section{Background of the study area}

Banso Baptist Hospital (BBH) is a Faith Based Health institution owned by the Cameroon Baptist Convention Health Services (CBCHS). BBH is a not-for-profit and apolitical organization. BBH developed out of a small government cottage hospital which included small buildings with about 20 beds. In an interview with Pa John Bah (of late) one of the first staff of the hospital on $4^{\text {th }}$ November 1998, he described how he began working with the General Hospital Kumbo (BBH under the government) in 1940. In 1949, the Baptist Mission under the leadership of Dr. Paul Gebauer purchased the General Hospital from the government of Cameroon for two shillings. Late Dr. Leslie M. Chaffee was the first Missionary doctor to start working in BBH as a Medical doctor until his death in 1973. Both Dr. Gebauer and Dr. Chaffee were American Missionaries. BBH is located in Kumbo Nso, Bui Division of the North West Region of Cameroon, and some 110 kilometers north west of Bamenda the regional headquarters. It is the oldest among the five hospitals, thirty integrated health centers and forty-one primary health centers run by the CBCHS. It has 250 beds with over 650 employees. It has many departments just like any normal African Hospital ranging from the outpatient, inpatient (wards=pediatrics, female, male and surgical), maternity, investigation (laboratory, X-Ray, Ultrasound), eye, dental, pharmacy, maintenance, medical records, housekeeping and catering, administration, training school for health personnel, security, physiotherapy, chaplaincy/ social services and a treatment center for people living with HIV/ AIDS and other chronic conditions (TB and palliative care). It is one of the referral hospitals in the North West Region of Cameroon and currently serves as the district hospital for Kumbo West District. Banso Baptist hospital is a huge structure. In 2015 only, Banso Baptist hospital consulted 83,924 outpatients, admitted 7,729 patients, performed 6,010 surgeries (major and minor) and conducted 1,341 deliveries. The eye department registered 8,884 and the dental department 4,230 patients respectively this same year (CBCHB Annual Health Management Information System Report of December 315t, 2015).

A hospital of this magnitude with the volume of activities as highlighted for 2015 alone will need a very large storage space for filing of medical records in the future but the space is limited. Also, delays in calculating patient bills manually, errors and delays in updating staff salaries and bonuses, some medication errors and overcrowding in the dispensary was noticed. A well-structured and customized Electronic-Based Health Information System in the hospital will help to bridge these gaps.

\section{Methods}

This was a retrospective hospital-based study. The instruments used for data collection were structured interviews, focus group discussions and review of past records in the medical records unit of the hospital. The staff who were interviewed were the hospital administrator, medical office in charge, three nursing supervisors, eleven heads of departments, four staff of the medical records unit and three staff of the central data management unit of the organization. Our interview was simply to know the position of the respondents on the present paper-based health management information system, time taken to retrieve a medical record from the medical records department, the tidiness of the unit, their computer knowledge and view on computerization of the medical records. Medical records were reviewed for a period of five years from 2012 to 2017. This was to help us ascertain the increase in the volume of activities in the hospital over time.

\section{Summary of major findings}

It has been seen clearly that the focus in the health care sector is turning towards electronic health information systems to better manage the problems which the paper-based systems have not been able to address. Also, the concept of globalization and information technology is catching the attention of all spheres of life today including health care provision. The following are some of the major findings I had in dealing with this subject:

A. BBH attended to 36,681 in-patients and 405,239 outpatients for the period of five years and the numbers continue to increase per year. To handle the activities of all these patients manually has not been easy.

B. Due to limited storage space, patient's medical records are stored only up to ten years. Any visit at the eleventh year to $\mathrm{BBH}$, no records will be available for the patient. Though these documents are scanned and stored in CDs before the hard copies are destroyed, this is no guarantee because of breakages, computer viruses and misuse.

C. At the dispensary/pharmacy, it was noted that there are lots of billing errors, poor stock management, inaccurate prescribing habits and limited awareness of close substitute for drugs by Screeners/Doctors, and long waiting time averaged at 1 hour for patients.

D. The process of coming up with the final bill for drugs, procedures, supplies and other services rendered to the patients especially In-patients during their time of stay in the hospital is very slow. It takes approximately 1 to 1 hour 30 minutes for a patient to get his/her bill summarized and presented to him/her for settlement after discharge. 
E. There is the problem of late submission of reports by satellite stations and other departments in the hospital to the Medical Records office for analysis which also delays for up to 7 days the process of reporting to the various stakeholders.

F. HIV and AIDS top the chat with 642 deaths recorded during the period almost $49 \%$ of the total deaths recorded for the period. This indicates that this disease is still a major public health problem.

G. Of the 441,920 patients (both in and out) treated in $\mathrm{BBH}$ during the period under study, 27,333 were treated of malaria which indicates that of every 100 persons who visit BBH about 7 are diagnose of malaria. This will not be as alarming as in other areas, but malaria still remains also a major concern.

H. Statistical data is useful in monitoring and evaluation, planning and in appraisal of work done by various cadre of staff in an establishment.

I. For medical records to be adequately completed, all the staff must recognize the fact that good patient care requires adequate information and try to document this information as much as possible.

J. Adequate and accurate health information (data) is needed to adequately meet the needs of each health care institution.

K. Although the paper based medical documentation is tedious and time consuming, the MR staff of BBH have been committed to providing as near accurate health information as possible.

L. The use of electronic health information systems in hospitals in Cameroon just like in most African countries is not yet popular but many health care providers are interested in getting this started.

M. There must be a well-structured and organized paperbased documentation before conversion to electronic-based otherwise, it is to be expected that bad paper-based documentation will be faithfully transformed into bad computer- based documentation.

N. Medical documentation provides four important objectives that is, in patient care, administration, quality management and education and in research.

0. Every business has an information value chain, in which raw information is systematically acquired and then transformed through various stages that add value to that information.

P. The study of information systems is a multidisciplinary field. No single theory or perspective dominates.

\section{Recommendations}

After a careful study of information systems in general and health information systems in particular with the situational analysis of $\mathrm{BBH}$, the author has the following recommendations to make in order to introduce an electronic-based health information system to function side by side the paper-based system which is currently in use.

A. With the present volume of activities in BBH, an electronicbased health information system is very necessary. It could be introduced gradually beginning with drugs management and later to billing because these two areas have major manual errors that are often costly to the hospital.

B. An IT specialist could be hired to develop the system adapting it to the local realities and train the hospital staff on how to use it instead of buying an already existing system which may be very costly and difficult to manage.

C. Constant communication between the dispensary and the Screeners/Doctors is very necessary. This could be every morning to let them know which drugs are available and which are out of stock and which close substitutes are available to avoid the prescription of drugs that are not in stock.

D. Bill clerks are supplied with well-functioning calculators and their number increased from five to eight to speed up with the bill's calculation process especially for in-patients.

E. Staff at all levels be well educated on the importance of adequate collection of patient information and documentation both to the patient and the hospital.

F. Computers and other needed equipment could be budgeted for and bought progressively from 2015 to 2016 to reduce the total cost of getting all at once. In this case, the complete transformation could be implemented in 2017.

G. An automatic back-up generator will be very necessary for effective implementation of the electronic-based medical documentation since the Hydro-electricity supply is inconsistent.

H. Staff in critical reception areas in the hospital be encouraged to start getting themselves train in computer skills. The hospital could subsidize the cost of training.

I. Staff should be educated on existing MR content, data sources and encouraged to adequately complete all cards, admission and treatment forms for all patients attended to in the hospital. This will ease the work of MR staff.

\section{Conclusion}

Information technology is the direction the whole world is turning to now including the health sector. Therefore, introducing an electronic-based health information system in $\mathrm{BBH}$ at this moment is vital especially that the hospital attends to over 80,000 patients each year. This is a very large number for their data to be dealt with manually. Also, some of the congestion in front of the dispensary and the bills office can only be reduced if their processes are computerized.

\section{References}

1. Florian L, Wilhelm G, Reinhold H, Petra KG (2003) Medical data management. Health Informatics, USA. 
2. James MW, Eric JB, Frank R, Buckley S (2005) Implementing an electronic health record system. Public Health, USA.

3. Kenneth CL, Jane PL (2010) Management information systems $\left(12^{\text {th }}\right.$ edn), Pearson Education, USA.

4. Lehmann HP, Abbott PA, Roderer NK, Rothschild A, Mandell S, et al (2005) Aspects of electronic health record systems $\left(2^{\text {nd }}\right.$ edn), Health Informatics, USA.

5. Segen JC (2002) Concise dictionary of modern medicine. MaGraw-Hill, USA.
6. Margaret EA, Jeanne H, Ann PS, Marilyn MS, Josephine MS, Nursing dictionary. MaGraw-Hill, USA.

7. Patricia AP, Anne GP, Patricia S, Amy Hall (2017) Fundamentals of nursing ( $9^{\text {th }}$ edn $)$, pp. 1-1392.

8. Suzanne CS, Brenda GB (2010) Suddarth's textbooks of Medical-Surgical Nursing $\left(12^{\text {th }}\right.$ edn $)$, USA.

9. William MP, Robert JH, Jack RK, Business ( $2^{\text {nd }}$ edn), USA. 